\title{
An Internet Based Flood Warning System
}

\author{
X. H. Wang ${ }^{*}$ and C. M. Du \\ School of Planning, University of Cincinnati, Cincinnati, OH 45221-0016, USA
}

\begin{abstract}
Urbanization often is accompanied with increased overland flow and shorter time of concentration. The threat of flooding from such changes can be serious to residents and governments that are responsible for flood warning and flood damage reduction. This paper presents the development of a flood warning system by integrating Internet, Geographic Information System, and a flood model. It first delineates flooding areas in response to different rainfall amounts and land use scenarios, then overlays the flooding areas with other data layers to identify properties and streets potentially to be affected by the user-specified flooding event. Finally, results from the simulation and overlay analysis are published via Internet as tables and maps. A user may also compare difference between the flooding areas from two scenarios, such as different rainfall amount or different land use plans. This study demonstrates that based on the simulation of changes in land use patterns, the change of runoff and flooding areas can be visualized in a temporal and spatial context. The system can estimate the affect of land development on flooding impact to support better planning and development decisions. In addition, it can help identify critical areas for more effective emergency response. Finally, it can reach out to a broad user base to increase public awareness of flooding impact.
\end{abstract}

Keywords: Curve number, flooding, geographic information system, internet, internet mapping, land use, modeling

\section{Introduction}

Flooding occurs when water accumulation from rainfall exceeds the combined rate of outflow runoff and infiltration from an area. The excessive water raises and may cause damage to properties in the area. Flooding is one of the most common natural hazards. Communities experiencing threats from flooding must always be ready to response to flooding emergency. This paper presents an Internet-based Flood Warning Information System. Such a system serves three purposes. First, the system estimates where flooding will likely occur during a storm event to aid emergency responses. Based on information provided by the system, local governments can quickly response to emergencies and more importantly, to take action to alleviate flooding impact. Second, the system delineates and presents flooding areas under different rainfall amounts to increase public awareness of flood impact. The easily accessible feature makes it available for public education. People with better idea of the extent of a flooding event are more likely to be prepared to support preventive approaches. Third, the system demonstrates the relationship between flooding areas and land uses in a watershed. Such information can provide a foundation for developers, general public, planners and other stakeholders to reach a consensus on flood-conscious land development.

The development of a flood warning system requires the understanding of water flow and land surface features. Increasingly, Geographic Information System (GIS) and hydrological modeling have been used by communities to forecast and manage such emergency events (Brimicombe \&

\footnotetext{
* Corresponding author: xinhao.wang@uc.edu
}

Bartlett, 1996; Brun \& Band, 2000; Weng, 2001). Recent studies have demonstrated the potential of Internet in improving accessibility to spatial data and spatial data processing services (Abel et al., 1998; Kingston et al., 2000). The Internet has been employed as a distribution mechanism for GIS-based applications (Doyle et al., 1998). However, majority of Internet use is limited to map service: publishing maps onto the Internet. To add analytical functions, the system presented here let its users operate simulation model, view simulation results, perform queries and select layer for display. The system integrates GIS and hydrological modeling for delineating flooding areas, uses spatial analysis functions to identify flood-prone properties and utilizes Internet for remote access of maps and tables. An important feature of this Internet-based flood warning system is that the system can take a user's input to execute an analytical model. Further, the modeling results are added to a spatial database and become available to other users via the Internet. We choose the Internet user interface because it removes the limitation of a traditional decision support system that stores data, model, and user interface on a single computer (Bhargava \& Tettelbach, 1997). Developing an Internet-based GIS will provide remote access and sharing of geographic data to a broad user base (Peng \& Nebert, 1997).

\section{Flood Warning System}

GIS plays an important role in this flood warning system. It is used to develop a spatial database. During the system operation, GIS is used to analyze data and to produce additional data layers associated to each scenario. The design of the flood warning system is focused on the connection be- 


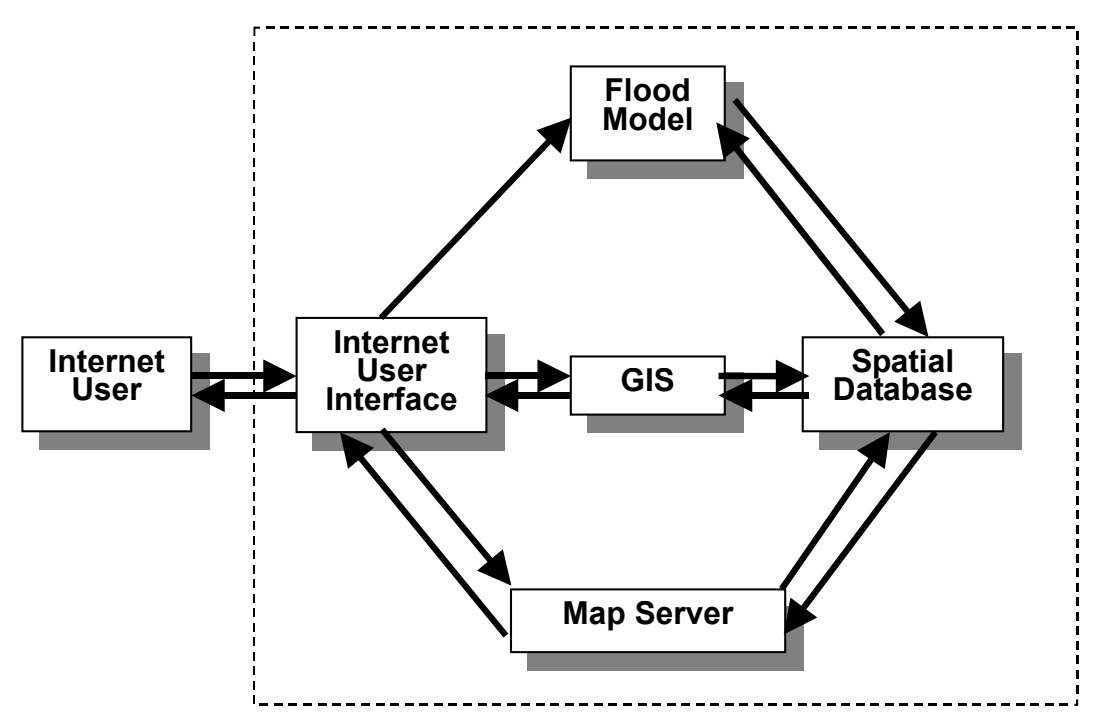

Figure 1. Structure of the Internet Based Flood Warning System.

tween GIS and simulation modeling through Internet technology.

\subsection{System Design}

Figure 1 displays the structure and data flow of the proposed flood warning system. Through this system a user may input different parameters for running a flood model and review flood modeling results. This feature demands dynamic operation in which running the flood model is executed only once for each scenario and the results become available to all users. To achieve this goal, the system must be able to keep track of all model runs and make them available when the modeling is done. The system consists of five components: a spatial database, a GIS analytical component, a flood simulation modeling component, a map service component, and an Internet user interface component. Those components are dynamically connected and each is responsible for a part of the system functions. Major data layers in the spatial database include land use, land surface elevation and soils as ArcView (Environmental System Research Institute, Inc. (ESRI), Redlands, CA) shapefiles. Attributes for different land uses and soil types are stored as tables in the database. These data are used to provide input data for the flood simulation model and for online display of flooding areas. Depending on the type of flood impact analysis, other data layers may be included such as streets, properties or building footprints. The flood simulation model delineates flood area for a given size of storm. The flood areas generated by a simulation model for different storm events are stored in the database as ArcView shapefiles. The GIS component manages the spatial database as well as provides overlay capabilities in order to identify the flooding impacts, such as properties and streets within potential flooding areas. The map server is used to present the modeling and overlay results as maps to the system users. The server allows the basic map viewing function, such as zooming in/out, pan- ning, identifying, and selecting via the Internet user interface. Therefore, a user will not need any additional software to use the system. The system is implemented to be user friendly with customized interface and scripts to support the "click and run" interface for most tasks. It can present both maps of area of interest and tabular data of the attributes of selected data layers.

\subsection{Flood Model}

The flood simulation model used to estimate runoff is a modified Runoff Curve Number (CN) method. The $\mathrm{CN}$ method was developed by the United States Department of Agriculture Natural Resources Conservation Service. The model estimates runoff for a given storm size. Determination of runoff depends on the amount of rainfall and potential maximum retention. The runoff equation is expressed as:

$Q=\frac{(P-0.2 S)^{2}}{(P+0.8 S)}$

where

$$
\begin{aligned}
& \mathrm{Q}=\text { runoff (depth), } \\
& \mathrm{P}=\text { rainfall (depth), } \\
& \mathrm{S}=\text { potential maximum retention after runoff begins } \\
& \text { (depth), calculated as: }
\end{aligned}
$$

$S=\frac{1000}{C N}-10$

This model presents simplified procedures for estimating runoff in small watersheds under various combinations of land uses using single-event rainfall data, and gives special emphasis to urban and urbanizing watersheds. To calculate the 
$\mathrm{CN}$ values and runoff, $\mathrm{Q}$, soil and land use data are used to reflect the variation of soil infiltration and subsurface permeability as well as surface intake. According to the USDA Natural Resources Conservation Service, soils are classified into four hydrologic soil groups (A, B, C and D) based on minimum infiltration rate (USDA, 1986). Land use often determines the type of land cover that also affects the amount of runoff generated from rainfall. Curve Numbers, ranging from 0 to 100 , are derived from both land cover and hydrologic soil group. Once the $\mathrm{CN}$ for an area is determined, the potential maximum retention, $\mathrm{S}$, can be calculated and then, runoff Q can be calculated for a given size of rainfall, $\mathrm{P}$.

Normally the $\mathrm{CN}$ model divides a watershed is into several areas depending on the soil and land cover conditions. Curve Numbers for different areas are determined and used to compute a composite Curve Number for the watershed. This $\mathrm{CN}$ is then used to calculate runoff depth for the outlet of the watershed. In this flood warning system, GIS spatial analysis functions are integrated into the $\mathrm{CN}$ model to form a cell-based calculation. Such integration adds land surface elevation to the runoff calculation. A detailed discussion of the approach can be found in Wang and Jin (2001). The modeling result is a water depth value for each cell. The flooding area is then delineated for the areas where water depth exceeds a threshold depth. The advantage of this approach is that it accounts for the accumulation of water from both rainfall and overland flow from upstream areas.

\subsection{Spatial Database}

Data used in this system include soil type, land surface elevation, land uses and watershed boundary. Those data may be obtained from different sources. There are increasing number of sources for acquiring data for such analysis, such as data developed by local governments or interpreted from remote-sensing imageries. Garbrecht et al. (2001) provide an excellent review of the data, data sources, and issues related to using spatial data in hydrological applications. In this study, we used land use data from Ohio Department of Natural Resources. Soil data were obtained from a GIS database maintained by a local organization. The data file contains polygons representing the soil types. From the same source we also got street and property boundary data. Land surface elevation data were downloaded from the Earth Resources Observation Systems (EROS) Data Center (EDC) of the U.S. Geological Survey's (USGS).

Several GIS functions were used to process the data. In order to use data from different sources together in a study, all of the data files must be converted to compatible formats and projection. Since the GIS functions were implemented with ArcView GIS 3, we have developed a database containing ArcView shapefiles, grid files, and dBase data tables. Land use is a polygon data layer showing the land use types. Because the locally defined land use classification was not the same as the land use classification used in the $\mathrm{CN}$ runoff model (USDA, 1986), A conversion table was prepared to match the two classification systems as shown in Table 1 . The
$\mathrm{CN}$ model classified soil types into soil hydro-groups. Therefore soil type hydro-group data were added to the soil type polygon attribute file.

The land elevation data were converted to ArcView grids and combined to form a continuous surface elevation grid. Normally, there are Sinks in elevation data due to errors in the source data. To create an accurate representation of flow direction and accumulated flow, it is best to use an elevation grid that is free of sinks. Therefore, the FILL function was used to create a depressionless elevation grid.

The soil and the land use polygon shapefiles were overlaid with the INTERSECT function in the ArcView Geoprocessing extension. Polygons with unique land use type and hydrologic soil group were created, based on which a Curve Number was assigned to each polygon. This polygon file was then converted to a $\mathrm{CN}$ grid file using the vector to raster conversion function. Each grid cell has assigned a Curve Number.

\subsection{Internet Map Server}

The Internet Map Server provides the capability of analyzing and displaying flood areas and their impact by publishing maps and tables through the WWW. It also allows system users to query map features. It is developed with ArcIMS, another product of ESRI. Some common functions, such as querying attributes, display data layers and zooming and panning, are available from clicking a few buttons. The out-of-box ArcIMS product has good HTML viewer and Java Viewer for easy user navigation. However, it dose not allow for customized GIS-based modeling and can hardly work with third party applications. To overcome this barrier we have developed a client viewer which can add a set of data and a new map service to the ArcIMS server after executing the flood model for a new scenario and make it available to system users. This dynamic feature is critical to support real-time decision making. A user can see a modeling result once it is completed as well as query data layers related to the new scenario.

\subsection{Internet User Interface}

Java based Servlet engine and Active Serve Page (ASP) is used to develop user interfaces for data input, scenario selection and to execute the flood model. As shown in Figure 2, a user needs to logon with a unique user ID. This serves two purposes. On the one hand, the system can keep track of its users and on the other hand, the model simulation results are saved on the server so that each user can run the model and view the modeling results independently. The dynamic viewer applies the fully customized graphic user interface (GUI) that supports mouse "click", "check" and "drag" operations. For example, in the Layer Control window, a user can select one or several data layers for display and control 
Table 1. A Land Use Conversion Table

\begin{tabular}{|c|c|c|}
\hline Local Land Use Category & \multicolumn{2}{|l|}{ USDA Classification } \\
\hline & \multicolumn{2}{|l|}{ Cover type and hydrologic condition } \\
\hline Residential & \multicolumn{2}{|l|}{ Residential: $1 / 3$ acre } \\
\hline Commercial And Services & \multicolumn{2}{|l|}{ Urban districts: Commercial and business } \\
\hline Mixed Urban Or Builtup Land & \multicolumn{2}{|c|}{ Newly graded areas (pervious areas only, no vegetation) } \\
\hline $\begin{array}{l}\text { Orchards, Groves, And Horticultual } \\
\text { Areas }\end{array}$ & Woods & $\begin{array}{l}\text { Fair: woods are grazed but not } \\
\text { burned, and some forest litter covers } \\
\text { the soil }\end{array}$ \\
\hline Confined Feeding Operations & \multicolumn{2}{|c|}{ Meadow-continuous grass, protected from grazing and generally mowed for hay } \\
\hline Cropland And Pasture & Row crops & SR + CR Good \\
\hline Shurb And Brush Rangeland & $\begin{array}{l}\text { Brush-brush-weed-grass mixture with } \\
\text { brush the major element }\end{array}$ & Good: $>75 \%$ ground cover \\
\hline Deciduous Forest Land & Wood-grass combination & Fair \\
\hline Evergreen Forest Land & Woods & Good \\
\hline Mixed Forest Land & Wood-grass combination & Good \\
\hline $\begin{array}{l}\text { Strip Mines, Quarries, And Gravel } \\
\text { Pits }\end{array}$ & Fallow & Bare soil \\
\hline
\end{tabular}

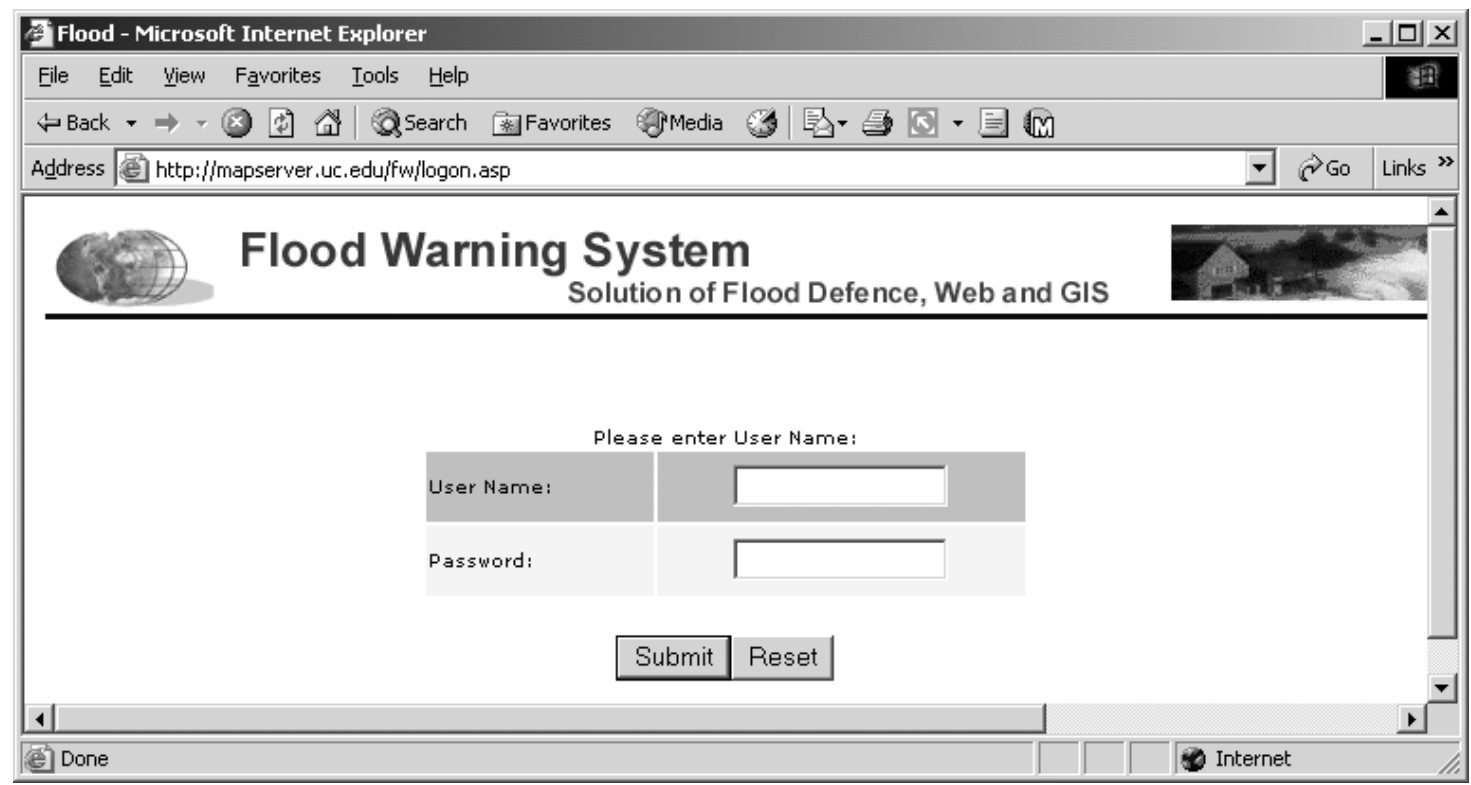

Figure 2. Flood warning system user interface. 
the drawing order. In addition, an active data layer can be assigned for interactive analysis and query (Figure 3).

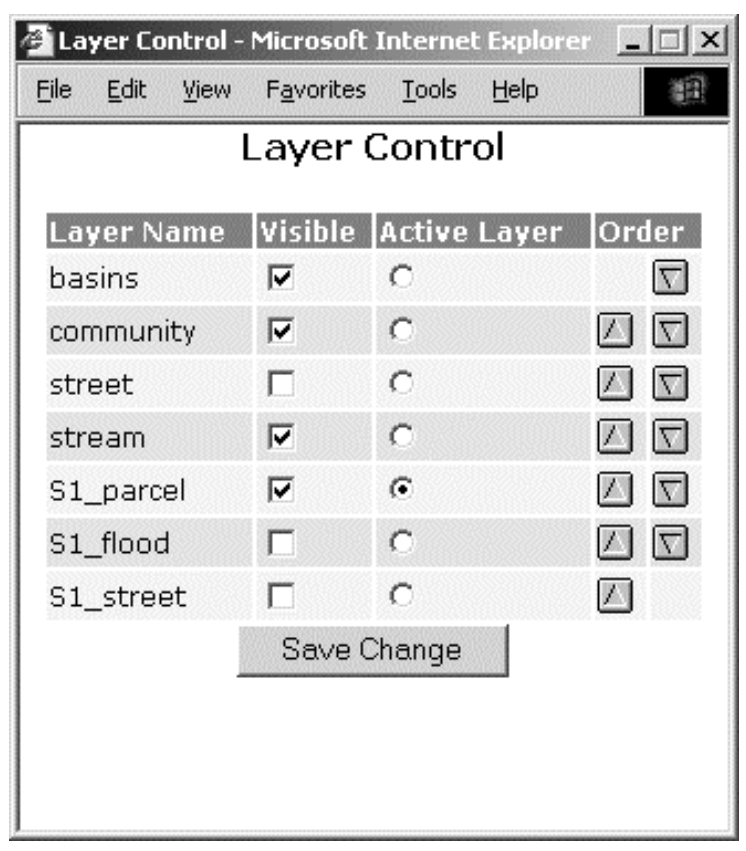

Figure 3. Data layer control window.

\section{System Operation}

The most common concerns by a local government regarding flood impact are the properties affected and streets that have to be closed. Therefore we have chosen these two data layers for evaluating flood impact. The flood warning information system can list the addresses for those properties that are within the identified flood area. Similar to the property data layer, street line data file is stored in the database. GIS spatial selection function is used to select the street segments that are within the flood area. Those street segments within a flood area can be displayed on a map, or be called by the user to be displayed in a table.

The user interface provides the necessary connection between the flood warning system and its user (Figure 4). A user may review a particular scenario (representing an amount of rainfall and a land use condition) or compare two scenarios. If the user is only interested in one scenario, he/she can choose a land use scenario and enter the rainfall amount. After the user submits the request, the program will search if flood simulation for the requested scenario was calculated before. If so the system will launch ArcIMS to publish data for the selected scenario. If no previous calculation is found, the system will execute the flood simulation model to calculate runoff and flood area for this scenario. After the simulation is complete, the system will display the scenario on the screen with multiple data layers. A user then is able to query, identify and select layers. In addition to viewing the results on the computer terminal, a user may print maps and tables.

The following figures illustrate examples of using the flood warning system. After a user specifies a land use and rainfall scenario, the system produces a map of the potential flooding area as shown in Figure 5. The affected properties and streets can be clearly seen in a zoomed-in map (Figure 6). Street segments that may be affected by the flood are also identified and highlighted in a tabular format (Figure 7).

In addition to reviewing a single storm event, a user may compare flood impacts under two scenarios. The comparison can be made for any combinations of rainfalls land use conditions. The user is able to compare the two scenarios with maps or tables. For example, a user may evaluate the impact of two scenarios independently as shown in Figure 8 ( $a$ and $b$ ). When a map showing the overlap of the two scenarios, a user can quickly identify the additional properties that are affected under one scenario but not the other (Figure 8c).

\section{Conclusions}

A flooding warning system is designed and implemented with GIS, hydrologic modeling and Internet technology. During a storm event, it is critical to accurately estimate where the flood is and how much impact it may cause. Although many sophisticated watershed models exist, they are rarely used as management tools because of difficulties in data collection and model implementation. Considering this, the integration of GIS and hydrologic modeling in this study serves as a useful tool for local government emergency response team and general public. Data required to operate the model are readily available in most municipalities (land surface elevation, soils, and land uses). The feature that data are maintained separately from simulation model makes it possible to eliminate the unnecessary costs of collecting duplicate data, to simulate under different sizes of storm events, and to compare results from different land uses.

Several considerations are addressed in the flood warning system. First, the system is intended for serving a wide range of users. Many of them may not have formal GIS or modeling training, which include but are not limited to knowing model limitations, data quality, and software operation. The Internet-based graphic user interface (GUI) provides a gateway for easy access to geographic data, spatial analysis and flood modeling. This can significantly increase the use of flood related data and information. Second, the system maintains data, flood model, and spatial data and analytical tools on the server. This centralized application allows for easy quality control, maintenance, and update. Third, the loosely-coupled integration approach leaves space for future improvement. For example, if a different flood model becomes available for the study area, it can easily replace the existing model without modifying the entire set-up of the system. The same is true for expanding an existing database, such as adding a new land use layer. This can significantly reduce the maintenance cost to keep the system effective for a long time. Fourth, making data and modeling result available on the Internet helps to support data sharing and collaboration among stakeholders. 


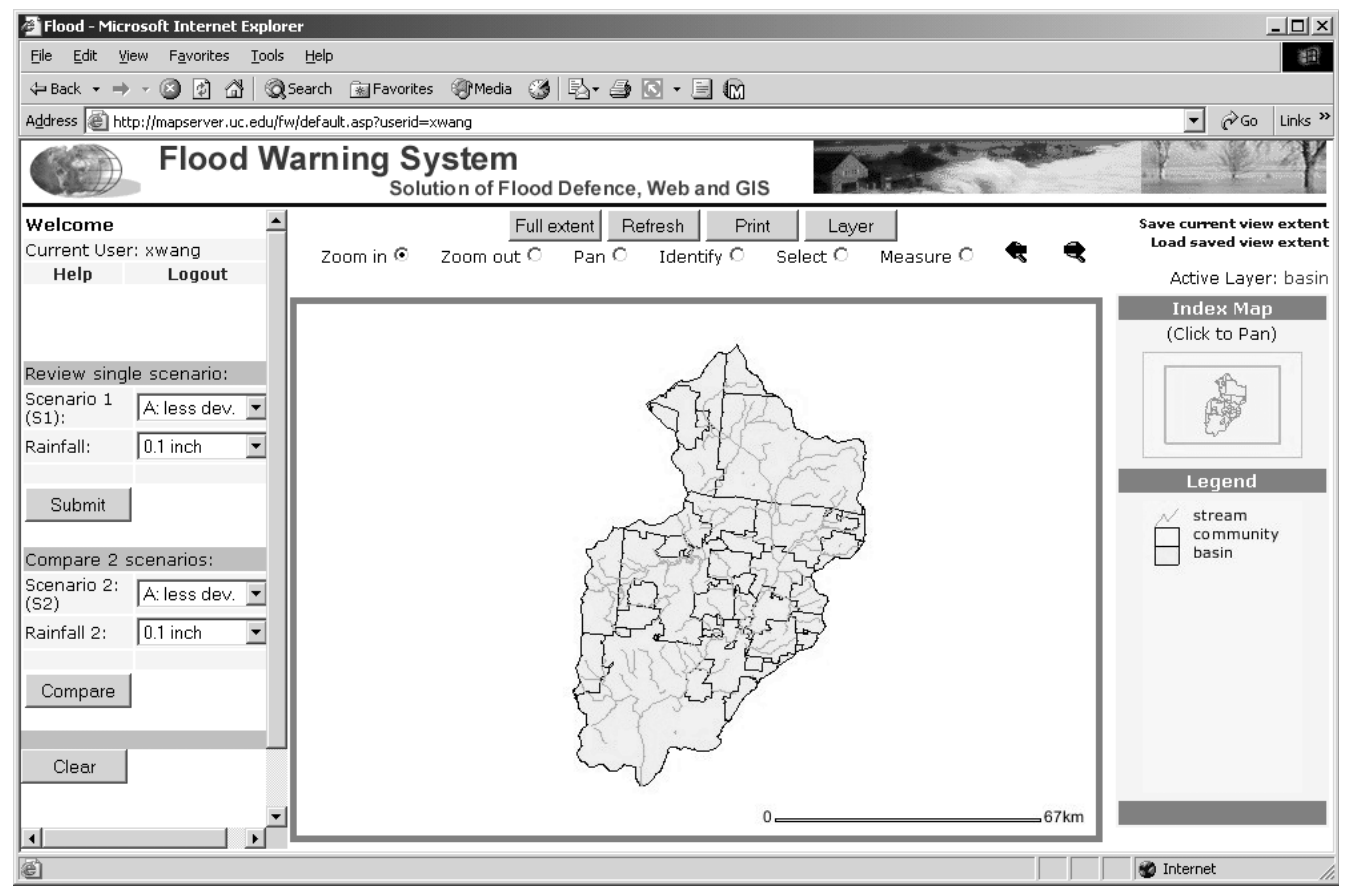

Figure 4. Main page of the flood warning system.

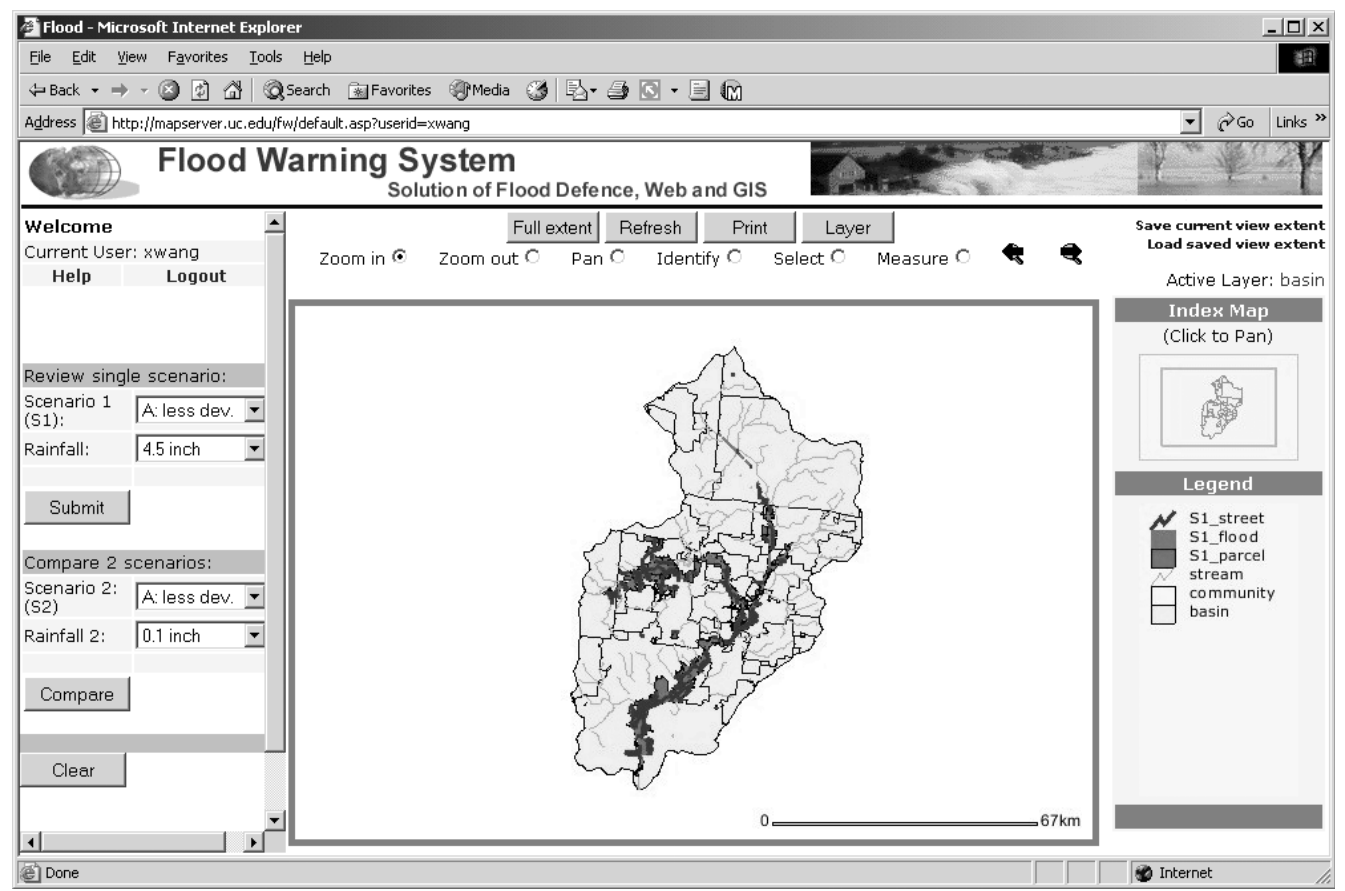

Figure 5. Flooding areas resulted from a user specified land use and rainfall scenario. 


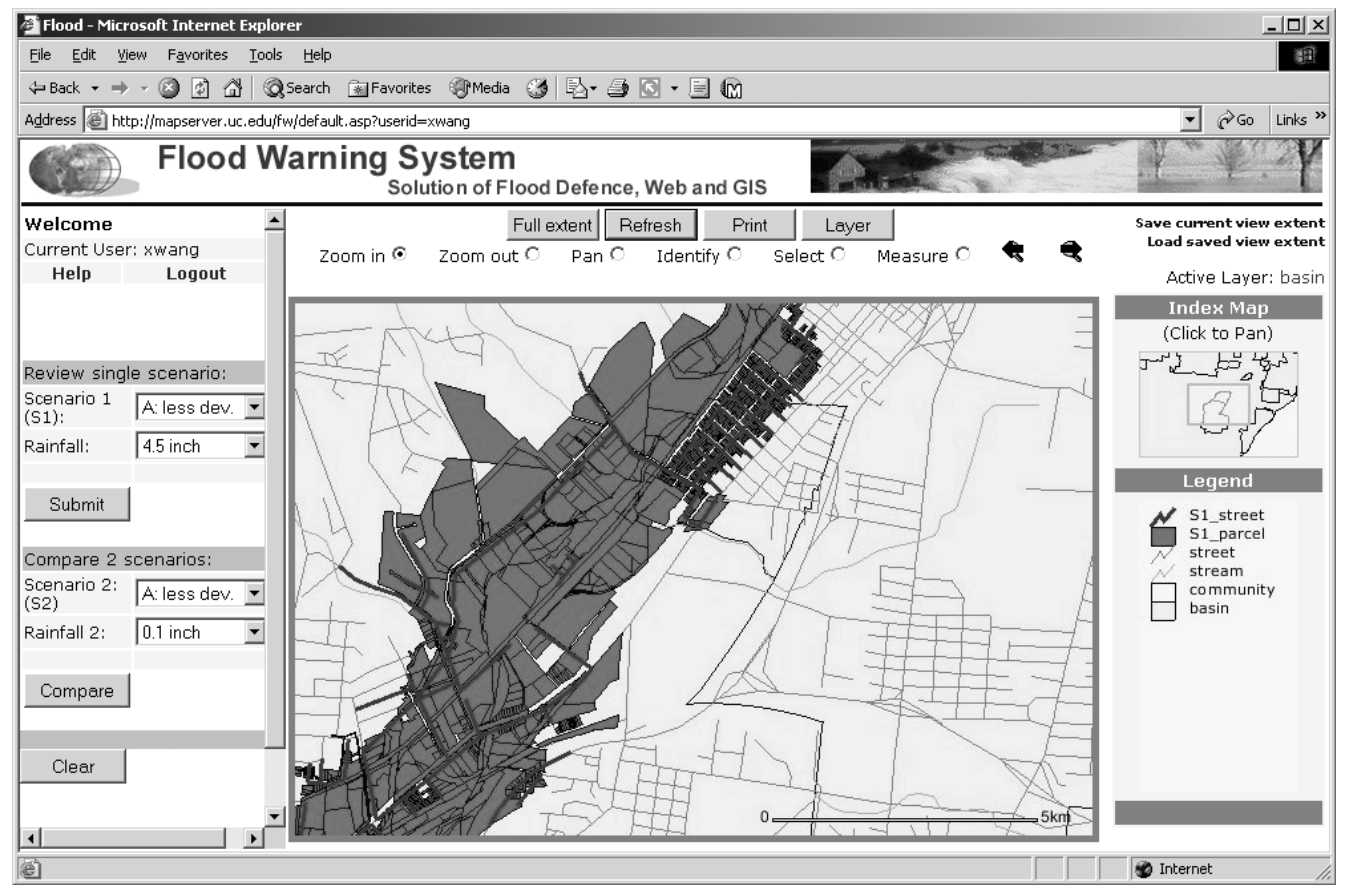

Figure 6. Properties and streets that may be affected by a user specified flood event.

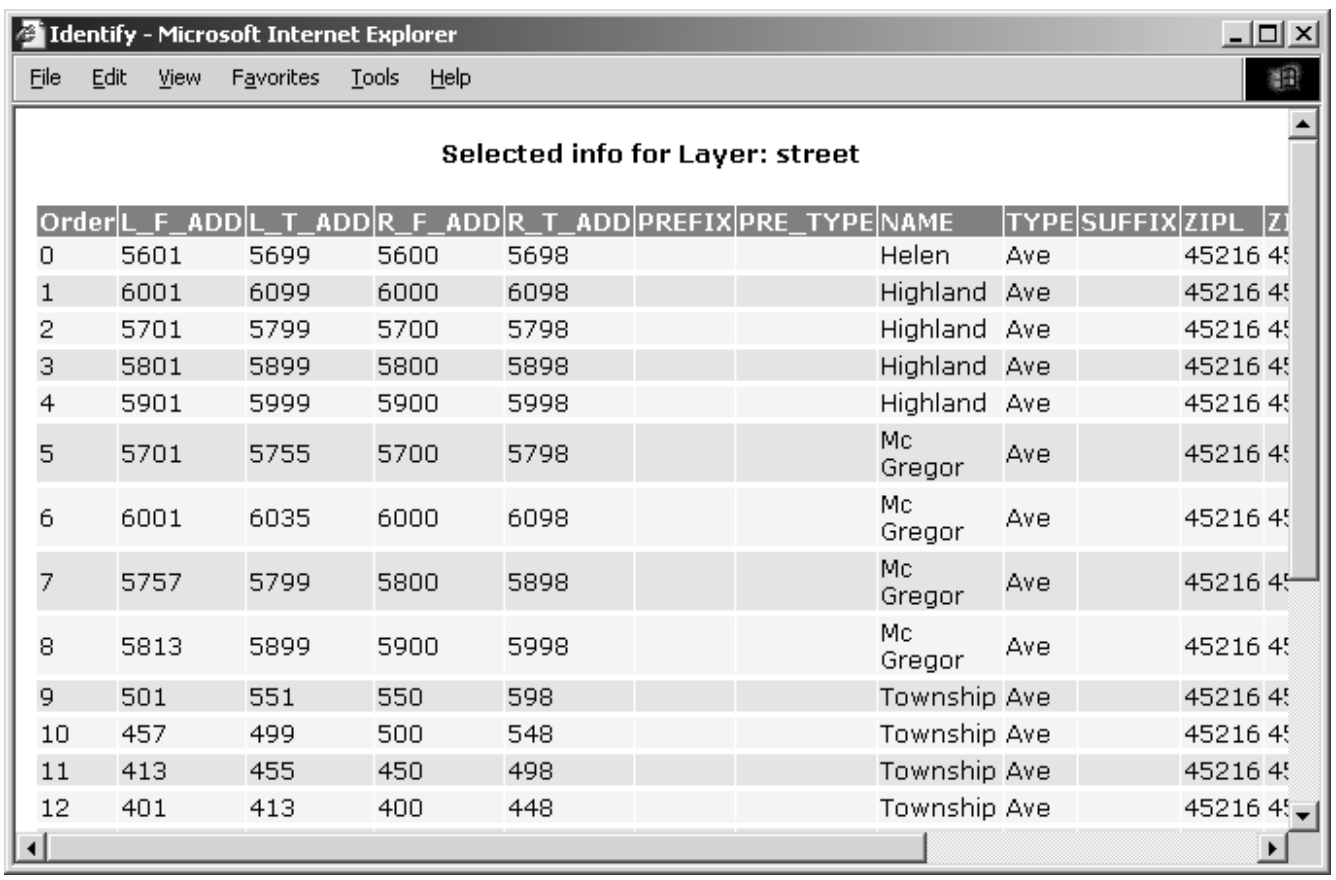

Figure 7. Attribute table of affected street segments. 


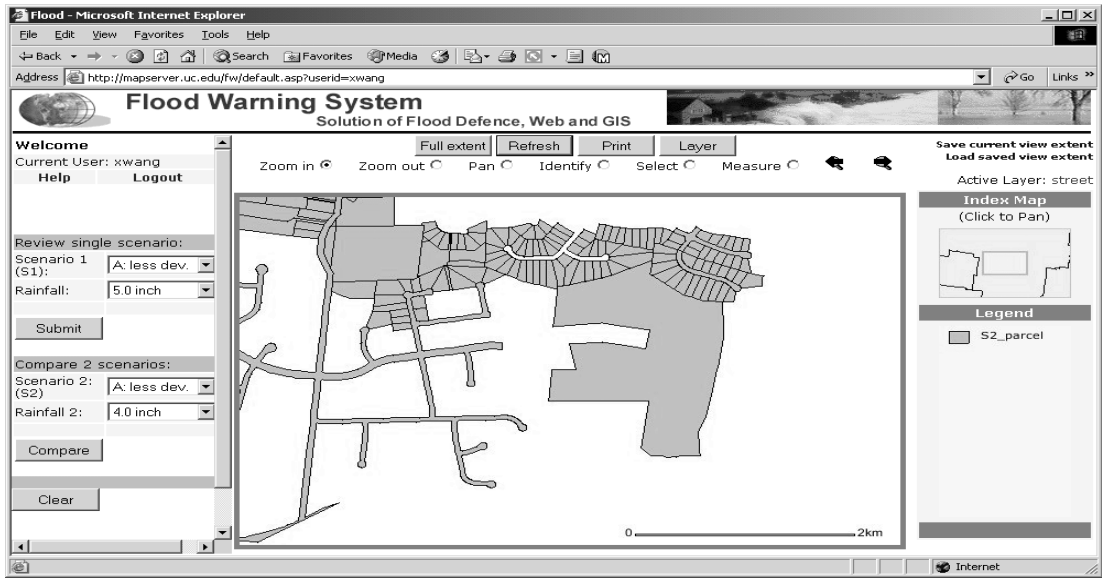

(a)

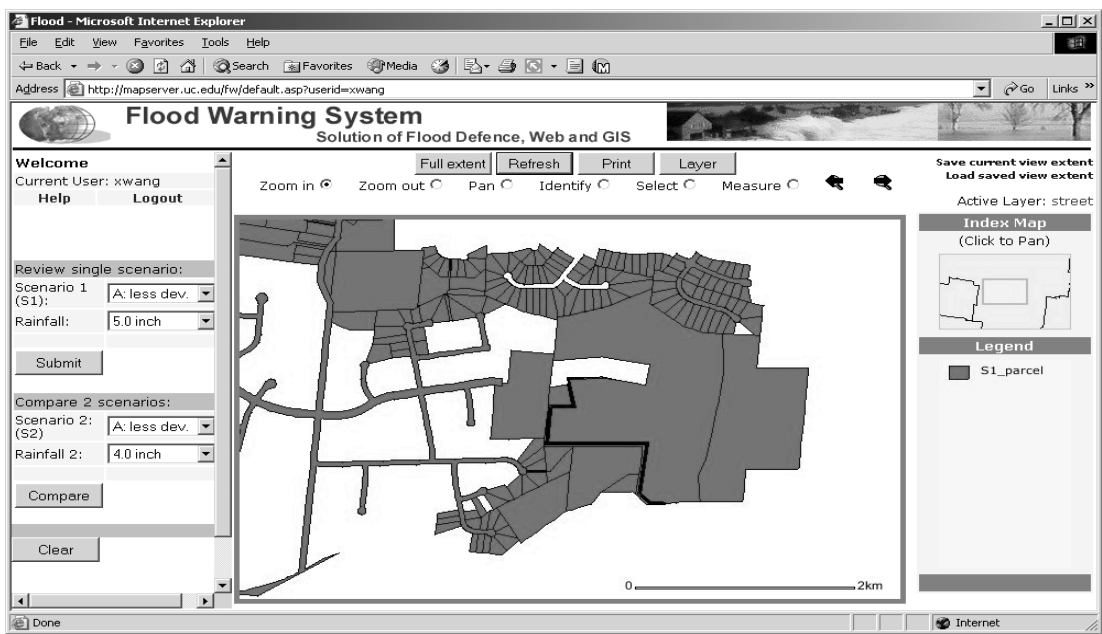

(b)

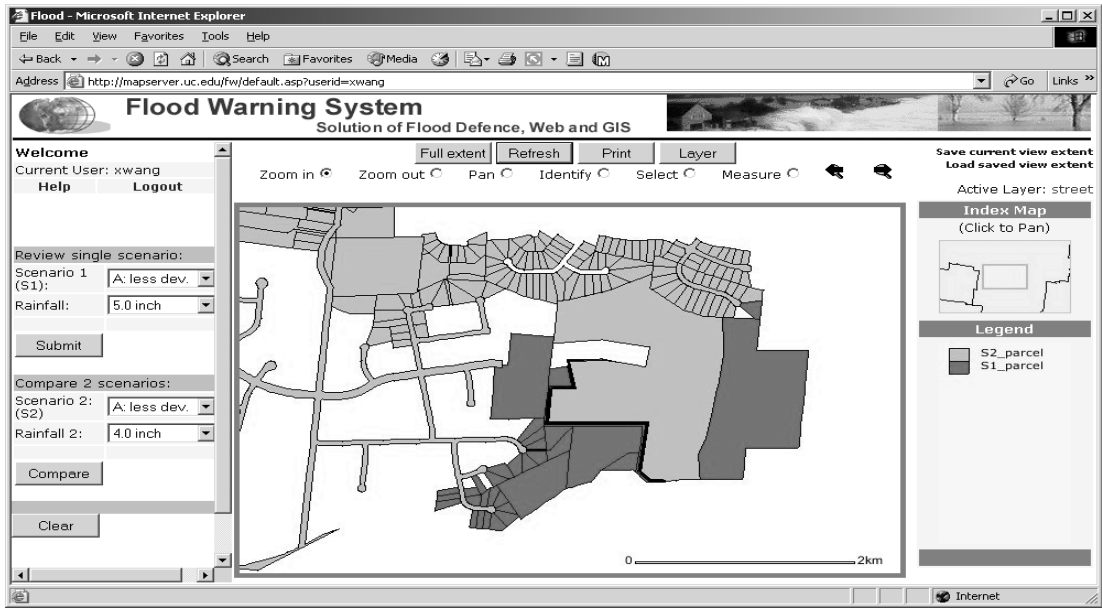

(c)

Figure 8. Comparison of two scenarios. 
The product from this study can be used as the primary information source to raise public awareness of the extent and nature of stream flooding as a consequence of urban growth. The user-friendly display and query capabilities allow dynamic manipulation of GIS database and a two-way communication between the system and its user. A user may interactively enter precipitation amount and select different land uses. These features will help to promote public participation in decision-makings related to reduce or prevent flooding damage.

\section{References}

Abel, D., Taylor, K., Ackland, R. and Hungerford, S. (1998). An exploration of GIS architectures for Internet environments. Comput., Environ. Urban Syst., 22(1), 7-23.

Bhargava, H. and Tettelbach, C. (1997). A web-based decision support system for waste disposal and recycling. Comput., Environ. Urban Syst., 21(1), 47-65.

Brimicombe, A.J. and Bartlett, J.M. (1996). Linking GIS with hydraulic modeling for flood risk assessment: the Hong Kong approach, in M.F. Goodchild, L.T. Steyaert, B.O. Parks, C. Johnston, D. Maidment, M. Crane and S. Glendinning (Eds.),
GIS and Environmental Modeling: Progress and Research Issues, Fort Collins, GIS World Books, CO, USA, pp.165-168.

Brun, S.E. and Band, L.E. (2000). Simulating runoff behavior in an urbanizing watershed. Comput., Environ. Urban Syst., 24, 5-22.

Doyle, S., Dodge, M. and Smith, A. (1998). The potential of web-based mapping and virtual reality technologies for modelling urban environments. Comput., Environ. Urban Syst., 22(2), 137-55.

Garbrecht, J., Ogden, F.L., DeBarry, P.A. and Maidment, D.R. (2001) GIS and distributed watershed models: 1: Data coverages and sources. J. Hydrol. Eng., 6(6), 506-514.

Kingston, R, Carver, S., Evans, A. and Turton, I. (2000). Web-based public participation geographical information systems: an aid to local environmental decision-making. Comput., Environ. Urban Syst., 24(2), 109-125.

Peng, Z.R. and Nebert, D. (1997). An Internet-based GIS data access system. J. Urban Reg. Inf. Syst. Assoc., 9(1), 20-30.

USDA (1986). Technical Release 55: Urban Hydrology for Small Watersheds, Department of Agriculture Soil Conservation Service, Washington, DC, USA.

Wang, X.H. and Jin, J. (2001). Assessing the impact of urban growth on flooding with an integrated curve number-flow accumulation approach. Water Int., 26(2), 215-222.

Weng, Q. (2001). Modeling urban growth effects on surface runoff with the integration of remote sensing and GIS. Environ. Manage., 28(6), 737-748. 